\title{
Qualidade da assistência pré-natal numa Unidade Básica de Saúde do município de Juiz de Fora - MG
}

\author{
Vanessa Monfardini Alves, Thirza dos Santos Nicácio, Renata Maria Souza Oliveira, Michele \\ Pereira Netto
}

\begin{abstract}
Resumo
A avaliação da qualidade do atendimento nas unidades de saúde constitui-se em uma potente ferramenta norteadora, para gestores e profissionais de saúde. A avaliação do pré-natal pode contribuir para melhorar a assistência às gestantes, diminuindo os índices de morbimortalidade materna e perinatal. A adesão e continuidade do pré-natal estão relacionadas com a qualidade da assistência efetuada pelo serviço e pelos profissionais de saúde. Tal adesão é essencial para redução dos elevados índices de mortalidade materna e perinatal verificados no Brasil. Analisar a adequação do processo da assistência pré-natal prestada às usuárias da Unidade Básica de Saúde do bairro Santos Dumont - Juiz de Fora, nos últimos 10 anos. Foi realizado um estudo retrospectivo de dados secundários, referente aos últimos 10 anos de gestantes atendidas na UBS do bairro Santos Dumont, em Juiz de Fora - MG. Os dados foram coletados entre janeiro e junho de 2016. Foram coletados e analisados os dados referentes ao pré-natal, e comparados com as recomendações do Ministério da Saúde sobre a atenção à saúde de gestantes, que recomenda entre outros, os seguintes procedimentos: Classificação de risco gestacional, mínimo de 6 consultas, sendo 1 no primeiro trimestre, história clinica, exames físicos e exames complementares. Os dados foram tabulados e processadas no software SPSS, versão 17.0, por meio de análises descritivas básicas. Foram avaliados no total de 146 prontuários. Fator importante para conter nos prontuários é o risco gestacional, contudo, dos prontuários avaliados apenas 18,49\% apresentavam essa informação. Com relação ao calendário de consultas, $15,1 \%$ fizeram no mínimo de 6 consultas e $59 \%$ realizaram a primeira consulta no primeiro trimestre. Em relação à história clinica e identificação, 32,2\% de prontuários com informação sobre a escolaridade da gestante; $32,9 \%$ sobre raça; $60,95 \%$ com idade; doenças pessoais e antecedentes familiares em $46,57 \%$ e $30,82 \%$; uso de álcool/drogas/tabaco em $33,56 \%$. Idade da menarca estava presente em 30,1\% dos prontuários. Já em relação ao número de gestações e partos, a informação estava presente em $82,9 \%$ dos prontuários. Sobre os dados da gestação atual, a DUM foi informada em $76,02 \%$ e a DPP em $89,72 \%$; a pesquisa de edema em 63,69\%; suplementos de ácido fólico e sulfato ferroso em 60,27\% e 48,63\% respectivamente. Entre os exames físicos, a avaliação do IMC deve ser idealmente realizada em todas as consultas, contudo a altura foi descrita em apenas $44,5 \%$ dos prontuários, o peso em $65,1 \%$ e a altura uterina em 23,3\%. Sobre os exames complementares, $34,2 \%$ e $32,9 \%$ apresentavam informação sobre hemoglobina e glicemia. Tendo em vista a relevância da assistência nutricional no pré-natal e a importância das equipes de saúde na ampliação dessa cobertura, reforça-se através deste estudo que as ações de assistência devem ser feitas em conformidade, assim como seu registro, garantindo uma melhor qualidade da assistência e da informação.
\end{abstract}

Descritores: Assitência pré-natal; Prontuários; Acompanhamento da gestante. 